\title{
INTERNAL DAMAGE EVALUATION OF CFRTP CUT BY A CIRCULAR SAW
}

\author{
KAZUTO TANAKA, TAIKI YAMASHIRO \& TSUTAO KATAYAMA \\ Department of Biomedical Engineering, Doshisha University, Japan
}

\begin{abstract}
In recent years, due to the serious environmental issues, the development of the gasoline mileage improvement technology has become essential in the automotive industry. Weight-saving of the car body can contribute to improving the gasoline mileage. CFRP (Carbon Fiber Reinforced Plastics) are widely used as structural material for airplanes, various kinds of sports gear and premium automobiles because of their low density and high performance in mechanical properties. In CFRP, CFRTP (Carbon Fiber Reinforced Thermoplastics) are expected to be used for lightweight component parts because of their high recycling efficiency and high productivity. Accordingly, a high-efficiency machining method of CFRTP has been needed; however, CFRTP are known as difficult-to-machine materials. Delamination and huge burrs are major problems in CFRTP cutting. Although a circular saw that can be used at high speed is usually used as a cutting tool, the internal damage of CFRTP resulting from machining has not been clarified yet. In this study, in order to evaluate the influence of cutting speed on the internal damage of CFRTP cut by circular saw, the internal damage depth and the temperature of specimens during cutting process were measured. The internal damage occurred by circular saw processing and the internal damage depth were decreased in the case of fast cutting speed. The temperature of the specimen was increased in the case of slow cutting speed because of the longer contact time of the circular saw with the specimen.
\end{abstract}

Keywords: CFRP, CFRTP, difficult-to-machine, circular saw, internal damage depth, cutting speed, temperature.

\section{INTRODUCTION}

Recently, due to the serious environmental issues, the development of the gasoline mileage improvement technology has become essential in the automotive industry, which reduces carbon dioxide emission [1], [2]. The technology includes improvement of the efficiency of the engine, the energy regeneration system, and the weight-saving of the car body. Especially, weight-saving of the car body can contribute to improving the gasoline mileage [3], [4]. CFRP (Carbon Fiber Reinforced Plastics), which are useful for weight reduction and decreasing fuel consumption, have recently been applied to structure elements of airplanes, automobiles, and so on because of their low density and high performance in mechanical properties [5]. In CFRP, CFRTP (Carbon Fiber Reinforced Thermoplastics) are expected to be used for lightweight component parts because of their high recycling efficiency and molding speed [6], [7]. Accordingly, a high-efficiency machining method of CFRTP has been needed; however, CFRTP are known as difficult-to-machine materials. Delamination and huge burrs are major problems in CFRTP cutting [8]. Although a circular saw that can be used at high speed with low cost is usually used as a cutting tool, the internal damage of CFRTP resulting from machining has not been clarified yet.

In this study, in order to evaluate the influence of cutting speed on the internal damage of CFRTP cut by circular saw, the internal damage depth and temperature of specimens during cutting process were measured. 


\section{MATERIALS AND EXPERIMENTAL PROCEDURES}

\subsection{Materials}

CFRTP laminated materials were molded by the high-speed compression molding method [9]. As the molding condition: molding temperature was set at $280^{\circ} \mathrm{C}$, molding pressure was set at $2 \mathrm{MPa}$ and molding time was $60 \mathrm{~s}$. As the reinforced materials, non-crimp stitched carbon fabrics (NCF, $300 \mathrm{~g} / \mathrm{m}^{2},\left[0^{\circ} / 90^{\circ}\right]$, Toho Tenax), which are PAN-based carbon fibers being stitched together by polyester sewing thread, were used. Non-woven fabric (prototype, Kuraray Co., Ltd., Japan $50 \mathrm{~g} / \mathrm{m}^{2}$ ) of Polyamide 6 (PA6, Ube Industries, Ltd., Japan) was used for the matrix of the specimens. The CFRTP laminated materials were used for the specimens to be machined, which were $100 \mathrm{~mm}$ long, $25 \mathrm{~mm}$ wide and $2 \mathrm{~mm}$ thick.

\subsection{Cutting of CFRTP and internal damage evaluation}

An electric circular saw (Makita Co., Ltd., 5834BA) with a tip saw blade (Tanitec Co., Ltd., LBS $192 \times 60$ ) with a blade diameter of $192 \mathrm{~mm}$ was used as the cutting tool. The specimens were cut in the vertical direction to the fiber direction of the outermost layer for CFRTP laminated specimen. Fig. 1 shows the cutting setup of CFRTP and Table 1 shows the cutting conditions. The cutting processes were carried out at constant cutting speeds of $8.5 \mathrm{~mm} / \mathrm{s}$ (HS1) and $2.4 \mathrm{~mm} / \mathrm{s}$ (LS1). After each cutting, the internal damage depth was measured

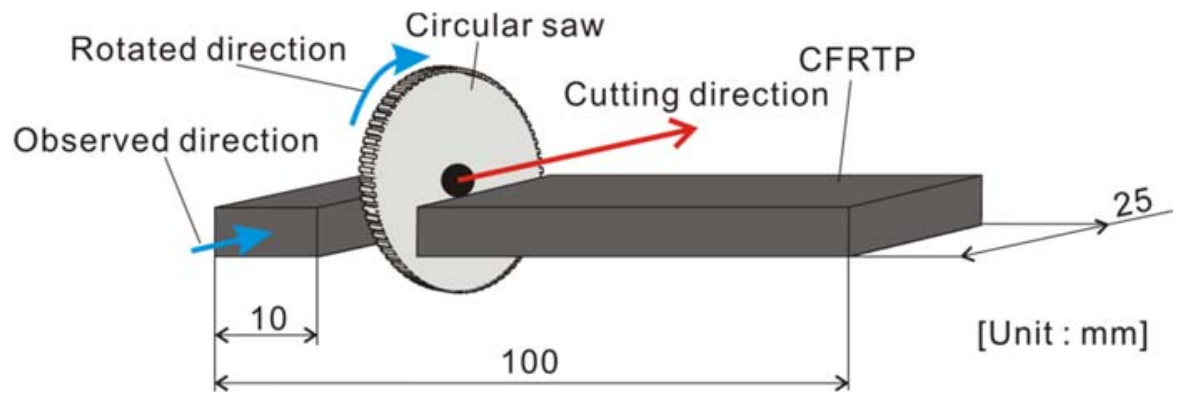

Figure 1: Schematic drawing of cutting setup.

Table 1: Cutting conditions.

\begin{tabular}{|c|c|c|}
\hline Specimen & \multicolumn{2}{|c|}{ CFRTP } \\
\hline Tool & $\begin{array}{c}\text { Circular saw } \\
\text { (5834BA) }\end{array}$ & $\begin{array}{c}\text { Circular saw } \\
\text { (LS0715F) }\end{array}$ \\
\hline $\begin{array}{c}\text { Number of } \\
\text { cutting edges }\end{array}$ & \multicolumn{2}{|c|}{60} \\
\hline Blade diameter & \multicolumn{2}{|c|}{$192[\mathrm{~mm}]$} \\
\hline $\begin{array}{c}\text { Thickness of } \\
\text { specimen }\end{array}$ & \multicolumn{2}{|c|}{$2[\mathrm{~mm}]$} \\
\hline $\begin{array}{c}\text { Length of } \\
\text { specimen }\end{array}$ & \multicolumn{2}{|c|}{$25[\mathrm{~mm}]$} \\
\hline Spindle speed & $4700\left[\mathrm{~min}^{-1}\right]$ & $4500\left[\mathrm{~min}^{-1}\right]$ \\
\hline Cutting speed & $\begin{array}{c}\text { HS1: } 8.5[\mathrm{~mm} / \mathrm{s}] \\
\text { LS1: } 2.4[\mathrm{~mm} / \mathrm{s}]\end{array}$ & LS2: $2.9[\mathrm{~mm} / \mathrm{s}]$ \\
\hline
\end{tabular}




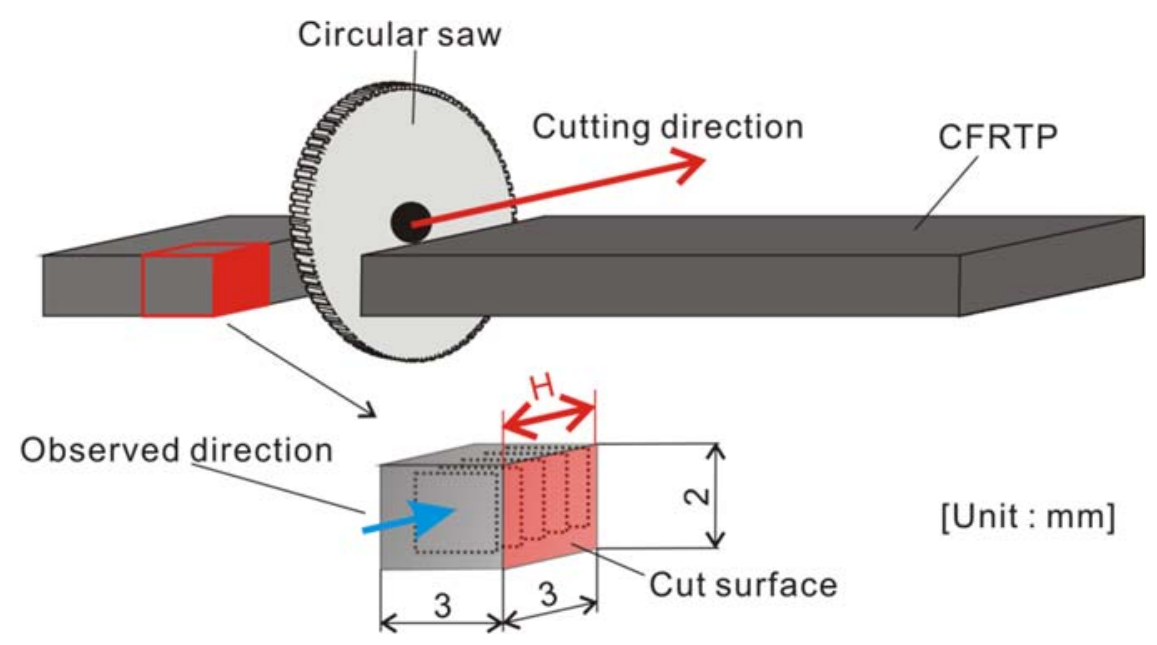

Figure 2: Schematic drawing of internal damage observation by high resolution 3D X-ray microscope.

by the digital microscope (Keyence Co., Ltd., VHX-5000) with the observed direction shown in Fig. 1. Fig. 2 shows the schematic drawing of the internal damage observation. The test specimens of $3 \mathrm{~mm} \times 3 \mathrm{~mm} \times 2 \mathrm{~mm}$, which were cut out from the position shown in Fig. 2, were observed by a high-resolution 3D X-ray microscope (Rigaku Co., Ltd., nano3DX).

\subsection{Temperature measurement of CFRTP during cutting process}

A slide type circular saw (Makita Co., Ltd., LS0715F) with the same tip saw blade as described in Section 2.2 was used as the cutting tool. In order to measure the temperature of specimens during cutting process the infrared thermal imaging camera (NEC Avio, TVS500 ) was used. As the cutting condition: cutting speed was set at $8.9 \mathrm{~mm} / \mathrm{s}$ (HS2) and 2.6 $\mathrm{mm} / \mathrm{s}(\mathrm{LS} 2)$.

\section{RESULT AND DISCUSSION}

\subsection{Internal damage evaluation}

Fig. 3 shows the cross sections of the cut specimens at the cutting speeds of HS1 $(8.5 \mathrm{~mm} / \mathrm{s})$ and LS1 $(2.4 \mathrm{~mm} / \mathrm{s})$ observed by the digital microscope. Internal damage, fiber bends, occurred regardless of cutting speed. The internal damage depth, which was defined as the length of bends fiber, was shown in Fig. 4. The internal damage depth of HS1 is smaller than that of LS1 by $68 \%$. It means that the smaller internal damage depth was observed in the case of fast cutting speed. Fig. 5 shows the result of the internal damages of the specimens at the cutting speeds of HS1 and LS1 observed by the high-resolution 3D X-ray microscope. $\mathrm{H}$ is the distance from the surface shown in Fig. 2. Internal cracks were observed in not only the specimen surface, where the cutting started, but also inside of the specimen. Fig. 6 shows the internal crack depth under the cutting speed of HS1 and LS1. For each cutting speed, the internal crack depth is almost same regardless of the distance from the surface. The internal crack depth of HS1 is smaller than that of LS1 by $40 \%$. It means that smaller internal crack depth was observed in the case of fast cutting speed. 


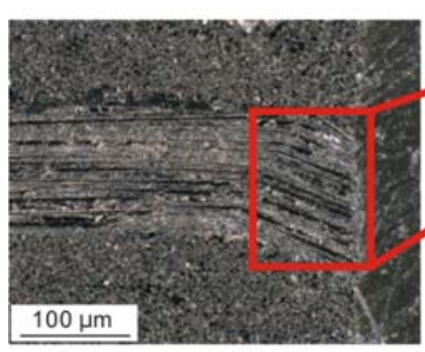

(a) HS1 $(8.5 \mathrm{~mm} / \mathrm{s})$

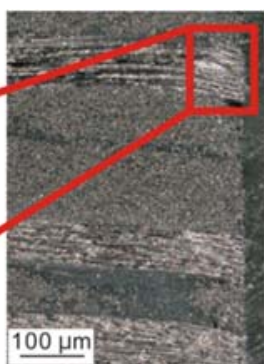

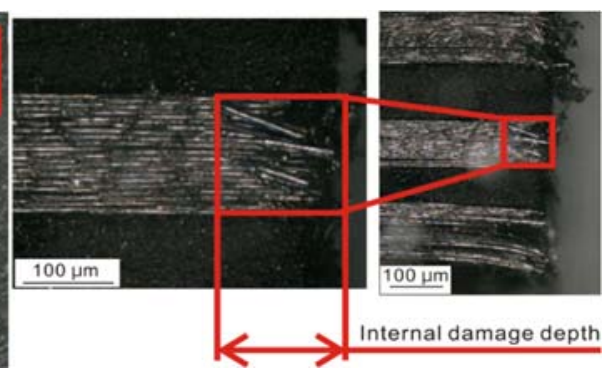

(b) LS1 $(2.4 \mathrm{~mm} / \mathrm{s})$

Figure 3: Cross section of the cut specimens.

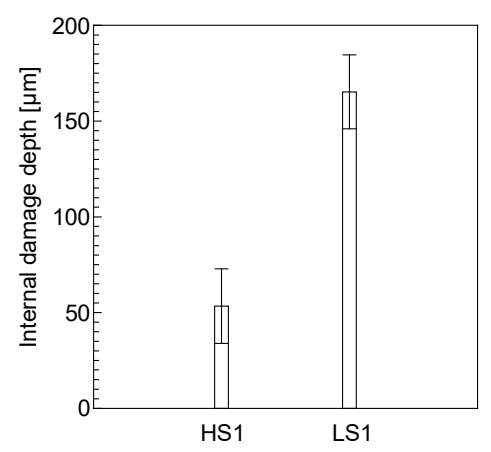

Figure 4: Internal damage depth $(\mathrm{N}=5$, mean $\pm \mathrm{S}$. D. $)$.

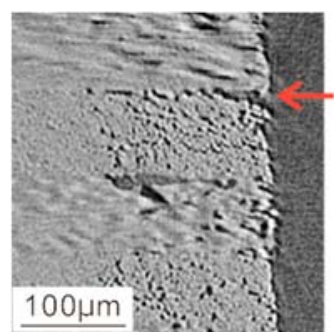

(i) $\mathrm{H}=0$

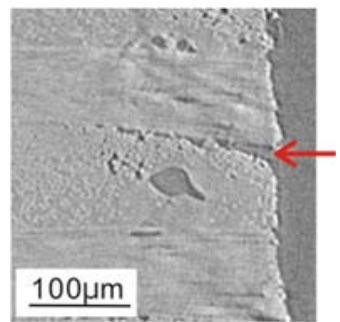

(i) $\mathrm{H}=0$

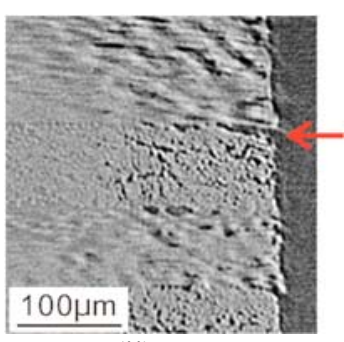

(ii) $\mathrm{H}=1.5$

(a) $\operatorname{HS} 1(8.5 \mathrm{~mm} / \mathrm{s})$

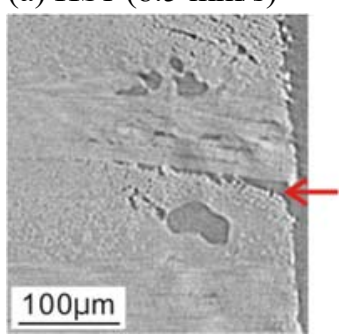

(ii) $\mathrm{H}=1.5$

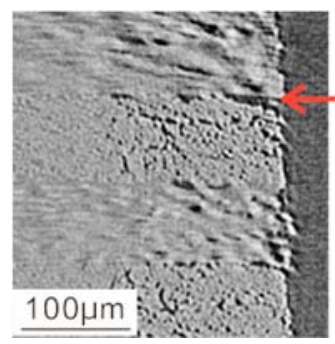

(ii) $\mathrm{H}=3.0$

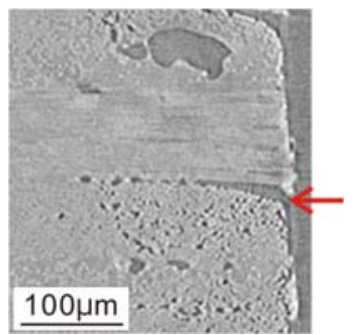

(ii) $\mathrm{H}=3.0$

(b) LS1 $(2.4 \mathrm{~mm} / \mathrm{s})$

Figure 5: Internal damages observed by the-high resolution 3D X-ray microscope. 


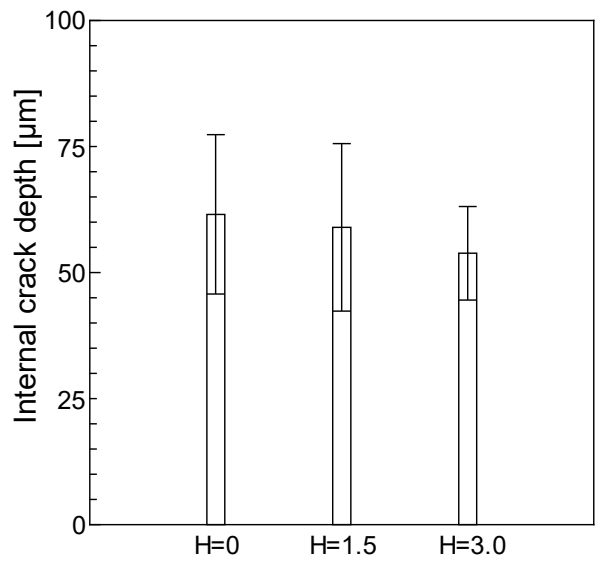

(a) $\operatorname{HS} 1(8.5 \mathrm{~mm} / \mathrm{s})$

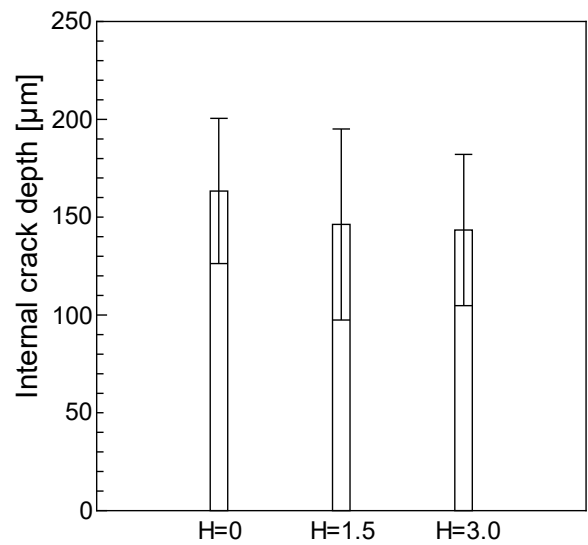

(b) LS1 $(2.4 \mathrm{~mm} / \mathrm{s})$

Figure 6: Internal crack depth.

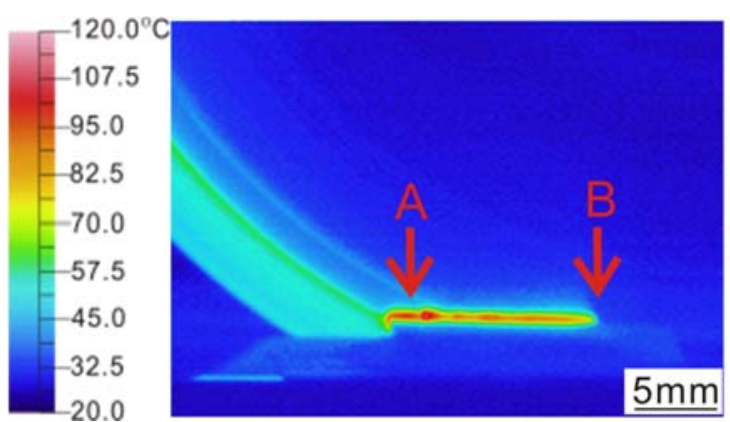

(a) $\operatorname{HS} 2(8.9 \mathrm{~mm} / \mathrm{s})$

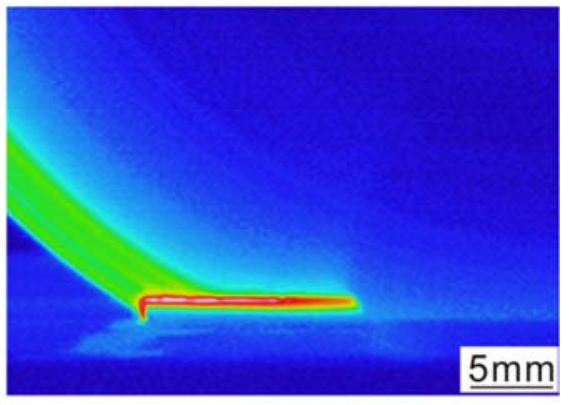

(b) LS2 $(2.6 \mathrm{~mm} / \mathrm{s})$

Figure 7: Temperature distribution of specimens during cutting process.

\subsection{Temperature of CFRTP during cutting process}

Fig. 7 shows the temperature distribution of the specimens at the cutting speeds of HS2 $(8.9 \mathrm{~mm} / \mathrm{s})$ and LS2 $(2.6 \mathrm{~mm} / \mathrm{s})$ observed by the infrared thermal imaging camera. When comparing the temperatures at $\mathrm{A}$ and $\mathrm{B}$ in Fig. 7, the temperature of $\mathrm{A}$ is higher than that of B. It is considered that the cutting temperature was increased due to friction heat. Fig. 8 shows the result of the measured maximum temperature in Fig. 7. The maximum temperatures of HS2 is smaller than that of LS2 by $20 \%$. In the case of slow cutting speed frictional heat was considered to be increased because of the longer contact time of the circular saw with the specimen. The maximum temperatures of both conditions are higher than the glass transition temperature of matrix resin $\left(60{ }^{\circ} \mathrm{C}\right.$ for PA6). Softening of the matrix resin is considered to occur during the cutting process. According to previous research, high temperature, which exceeds the glass transition temperature of thermoplastic resin, decreases the mechanical properties of Polyamide 6 resin [10]. It is considered that internal damage easily occurred because cutting temperature exceeded the glass transition temperature. 


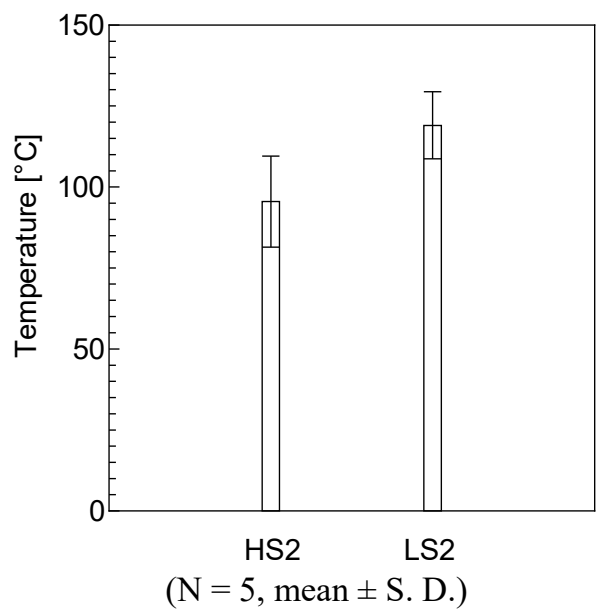

Figure 8: Maximum temperature of specimens at different cutting speed.

\section{CONCLUSION}

In this study, in order to evaluate the influence of cutting speed on the internal damage of CFRTP cut by circular saw, the internal damage depth and the temperature of specimens during cutting process were measured. The investigation yielded the following conclusions:

1. The internal damage occurred by circular saw cutting process was smaller in the case of fast cutting speed.

2. The frictional heat was increased in the case of slow cutting speed because of the longer contact time with the specimen.

\section{REFERENCES}

[1] Ministry of the Environment Government of Japan, The Transition of Internal $\mathrm{CO}_{2}$ Emissions by Department, Statistic of the Environment, Online. www.env.go.jp/doc/toukei/contents. 2016.

[2] United Nations Framework Convention on Climate Change, Report of the Conference of the Parties on its Twenty-First Session, Held in Paris from 30 November to 13 December 2015. Conference of the Parties, 21, p. 22, 2016.

[3] Shida, R., Tsumuraya, K., Nakatsuka, S. \& Takahashi, J., Effect of Automobile Lightning by CFRP on the World Energy Saving. The Ninth Japan International SAMPE Symposium, pp. 8-13, 2005.

[4] Ministry of Land, Infrastructure, Transport and Tourism Government of Japan, The Fuel Efficiency and $\mathrm{CO}_{2}$ Emissions of Passenger Vehicles, Statistic of The Fuel Efficiency in Automobile, Online. www.mlit.go.jp/jidosha/jidosha_fr10_000010.html. 2016.

[5] Takahashi, J., Development in Composites Technology for Reduction of Environmental Load. Journal of the Society of Materials Science, Japan, 57(8), pp. 852-855, 2008.

[6] Ishikawa, T., Overview of Carbon Fiber Reinforced Composites (CFRP) Applications to Automotive Structural Part, Focused on Thermoplastic CFRP. Japan Society for Precision Engineering, 81(6), pp. 489-493, 2015. 
[7] Terada, K., Carbon Fiber Reinforced Thermo Plastics Currently, Applications and Forecast. Journal of the Japan Society for Precision Engineering, 81(6), 2015.

[8] Higaino, T., Aoyama T. \& Ogawa H., Influence of Cryogenic Machining by Using Liquid Nitrogen on End Milling of CFRTP. The Japan Society of Mechanical Engineers, 81(832), 2015.

[9] Tanaka, K., Kohashi, N., Kinoshita, Y., Katayama, T. \& Uno, K., Compression Molding of Carbon Fiber Reinforced Thermoplastics Using Non-Woven Stitched Multi-Axial Cloth by Means of Induction Heating System. The Society of Materials Science Japan, 58(7), pp. 642-648, 2009.

[10] Fujiyoshi, T., Handbook of the Polyamide Resin, The Newspaper Company of Daily Publication Industry, pp. 84-91, 1988. 